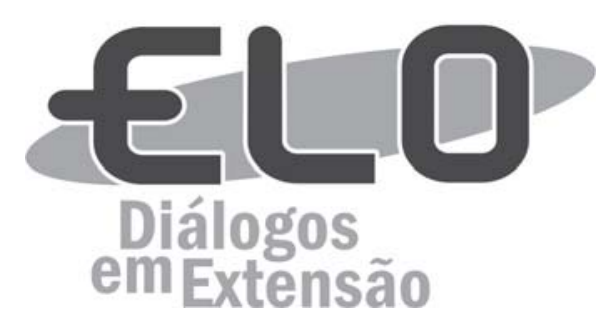

\title{
Gado homeopatizado, leite melhorado: um relato de experiência da Zona da Mata de Minas Gerais, Brasil
}

\author{
Lidiane Figueiredo dos Santos ${ }^{1}$ e Regina Aparecida de Figueiredo Santos
}

\begin{abstract}
Resumo: O crescente uso de produtos químicos no controle de parasitas de bovinos tem sido um dos grandes problemas enfrentados pela pecuária brasileira. Assim, diante da demanda dos alunos de uma escola do campo, localizada na Zona da Mata de Minas Gerais - Brasil, criou-se esse projeto, cujo objetivo foi fomentar novas práticas de produção no segmento pecuário. O projeto em questão iniciou-se na sala de aula, onde os alunos estudaram os principais ectoparasitas bovinos, a contaminação do leite por produtos utilizados em banhos contra os parasitas, o valor nutritivo do leite e o uso de seus derivados na alimentação. Os alunos também aprenderam os princípios da homeopatia e o seu modo de fabricação. A segunda etapa do projeto contou com aulas de campo, nas quais os alunos visitaram os agricultores da região e os ensinaram a fabricar e utilizar a homeopatia. Com o projeto, os agricultores da região passaram a usar a homeopatia como alternativa ao controle químico de parasitas.
\end{abstract}

Palavras-chave: Agricultores. Alunos. Leite. Parasitas.

Área Temática: Agroecologia. Educação.

\section{Homeopathic cattle, improved milk: an experience report from the Zona da Mata of Minas Gerais, Brazil}

\begin{abstract}
The growing use of chemicals in the control of bovine parasites has been one of the major problems faced by brazilian cattle raising. Thus, in the face of demand from the students of a rural school, located in the Zona da Mata of Minas Gerais - Brazil, this project was created, whose objective was to foster new production practices in the livestock segment. The project in question began in the classroom, where the students studied the main bovine ectoparasites, the contamination of milk by products used in baths against parasites, the nutritive value of milk and the use of its derivatives in food. Students also learned the principles of homeopathy and its mode of manufacture. The second stage of the project included field lessons, where students visited local farmers and taught them how to make and use homeopathy. With the project, farmers in the region began to use homeopathy as an alternative to chemical control of parasites.
\end{abstract}

Keywords: Farmers. Students. Milk. Parasites.

Ganado homeopatizado, leche mejorada: un relato de experiencia de la Zona de la Mata de Minas Gerais, Brasil

Resumen: El creciente uso de productos químicos en el control de parásitos de bovinos ha sido uno de los grandes problemas enfrentados por la ganadería brasileña. Así, ante la demanda de los alumnos de una escuela del campo, ubicada en la Zona de la Mata de Minas Gerais - Brasil, se creó ese proyecto, cuyo objetivo fue fomentar nuevas prácticas de producción en el segmento pecuario. El proyecto en cuestión se inició en el aula, donde los alumnos estudiaron los principales ectoparásitos bovinos, la contaminación de la leche por productos

${ }^{1}$ Doutoranda em Biotecnologia Vegetal, Universidade Estadual do Norte Fluminense Darcy Ribeiro (UENF), Av. Alberto Lamego, 2000, Parque California, 28.013602, Campos dos Goytacazes, RJ, Brasil, lidianefigueiredosantos@hotmail.com.

2 Pós-Graduada em Supervisão, Orientação e Inspeção Escolar pelo Instituto Superior Tupy e Professora da Escola Municipal Nossa Senhora de Fátima, s/n, Zona

Rural, 36.880-000, Muriaé, MG, Brasil. 
utilizados en baños contra los parásitos, el valor nutritivo de la leche y el uso de sus derivados en la alimentación. Los alumnos también aprendieron los principios de la homeopatía y su modo de fabricación. La segunda etapa del proyecto contó con clases de campo, donde los alumnos visitaron a los agricultores de la región y los enseñaron a fabricar y utilizar la homeopatia. Con el proyecto, los agricultores de la región pasaron a utilizar la homeopatía como alternativa al control químico de parásitos.

Palabras clave: Los agricultores. Estudiantes. La leche. Parásitos.

\section{Introdução}

A escola, em sua essência, tem o papel de proporcionar oportunidades para a sistematização e para a consolidação do conhecimento construído social e coletivamente, o que ocorre a partir da interação entre sujeitos e o ambiente em que vivem. Assim, não é possível desenvolver atividades educativas alheias aos anseios de sua comunidade. A escola deve permitir a vivência de processos democráticos de forma participativa e que envolvam alunos e comunidade (TIBA, 2006).

Nos trabalhos desenvolvidos em escolas do campo, a realização de atividades que englobem a realidade dos alunos é crucial. Desse modo, a escola desempenha um papel importante no fornecimento de alternativas aos problemas enfrentados pelas famílias do campo. Dentre esses problemas, destacase o crescente uso de produtos químicos no controle de parasitas responsáveis por consideráveis perdas no sistema pecuário brasileiro.

Na Zona da Mata Mineira, a pecuária de corte e a pecuária leiteira são as atividades provenientes da agricultura familiar e que desempenham um papel relevante na produção de alimentos e geração de renda (FRANÇA et al., 2009). No entanto, com os avanços no setor pecuário, cresce também o uso indiscriminado de produtos químicos para o controle de parasitas que atacam rebanhos bovinos, como carrapatos e moscas. Esses agroquímicos, além de serem onerosos, promovem a poluição do meio ambiente, uma vez que apresentam ação tóxica e contaminante, prejudicando toda a cadeia alimentar (leite e carne bovina) e os agricultores que manuseiam esse tipo de produto (ARENALES, 2006).

Uma alternativa para reduzir a utilização desses produtos químicos pode ser o uso de medicação homeopática, uma terapia de simples produção e de fácil aceitação por parte dos animais. A homeopatia se baseia no princípio do "semelhante cura semelhante", ou seja, um animal atacado por carrapato, por exemplo, pode ser tratado com homeopatia do próprio carrapato (esse princípio será explorado e expandido na sessão posterior). Sua utilização permite que os alimentos, como leite e carne bovina, cheguem ao consumidor livres de resíduos de medicamentos, o que mantêm os animais saudáveis e livres de substâncias tóxicas (PINTO e ALMEIDA, 2002).

Diante da importância de se desenvolver práticas sustentáveis com agricultores e atendendo a uma demanda de seus filhos (alunos da escola do campo) acerca da busca por alternativas às práticas de controle químico na pecuária, foi desenvolvido este projeto, cujo objetivo foi fomentar novas práticas de produção no segmento pecuário, além de desenvolver oralidade, leitura, escrita, produção de textos, conhecimentos matemáticos e científicos dos alunos da escola do campo.

\section{Metodologia}

O projeto foi desenvolvido na Escola Municipal Nossa Senhora de Fátima, situada na Comunidade de Bom jardim, município de Muriaé, localizado na Zona da Mata de Minas Gerais - Brasil, onde a pecuária leiteira é uma atividade desenvolvida por muitos produtores. Essa escola é constituída por uma turma multisseriada com alunos da Educação Infantil ( $2^{\circ}$ Período) e $1^{\circ}$ ao $5^{\circ}$ ano do Ensino Fundamental, e sempre procurou desenvolver projetos relacionados às questões ambientais que fazem parte da realidade dos alunos e da comunidade na qual estão inseridos.

A primeira etapa do projeto consistiu no estudo, em sala de aula, dos principais ectoparasitas bovinos (berne, mosca do chifre e carrapato), incluindo identificação de nome científico, alimentação, reprodução, características e curiosidades. Temas como a contaminação do leite por produtos utilizados em banhos químicos contra os parasitas dos bovinos, valor nutritivo do leite e o uso de seus derivados na alimentação também foram discutidos em sala.

O estudo da homeopatia como alternativa no controle dos ectoparasitas foi realizado por meio da construção de um mapa conceitual com seu histórico e princípios básicos. A Homeopatia, como prática popular, tem base legal na Instrução normativa $n^{0} 7$, publicada no Diário Oficial da União, que 
estabelece as normas para produção orgânica no Brasil e recomenda a aplicação da homeopatia pelos produtores rurais (BRASIL, 1999).

A homeopatia no meio rural é vista como proposta libertadora e humanitária. É um produto natural, criado pelo alemão Samuel Hahnemann em 1796 e baseado no princípio do "semelhante cura semelhante" (UFV, 2014). Um animal atacado por inúmeros carrapatos, por exemplo, pode ser tratado com a homeopatia do próprio carrapato. Faz-se, primeiramente, uma tintura com $40 \%$ do parasita para $60 \%$ de álcool a $70 \%$, que deve ficar em repouso por 14 dias. Após esse período, coa-se a tintura e adiciona 5 gotas da mesma em um frasco com $20 \mathrm{~mL}$ de álcool a $70 \%$ e agita 100 vezes. Feito isso, obtém-se a homeopatia $1 \mathrm{CH}$ (centesimal de Hanhnemann). Procede-se assim até o $6 \mathrm{CH}$ e está pronta a homeopatia que poderá ser misturada em açúcar, que, por sua vez, será incorporado em $30 \mathrm{~kg}$ de sal mineral próprio para a alimentação de bovinos, ficando este sal homeopatizado. Assim, o sal poderá ser oferecido diariamente aos animais e fará o controle natural dos ectoparasita, sem contaminar o leite, a carne animal e os produtores rurais.

Paralelamente aos estudos em sala de aula, foram realizadas aulas de campo, nas quais quatro famílias produtoras de leite participaram do projeto. O trabalho foi desenvolvido em duas etapas. $\mathrm{Na}$ primeira, foi realizada a coleta dos ectoparasitas (berne, mosca do chifre e carrapato) e confecção da tintura. Já na segunda etapa, realizou-se a confecção da Homeopatia (feita a partir da tintura) e o preparo do sal mineral homeopatizado.

A escola forneceu os frascos e o álcool para confecção da homeopatia e as famílias forneceram o sal a ser homeopatizado. A visita na primeira propriedade se iniciou com uma roda de conversa, em que os alunos falaram sobre as características dos ectoparasitas, os danos causados ao gado leiteiro e o uso dos carrapaticidas e inseticidas, que podem ser substituídos por um produto homeopático (Figura 1). Eles apresentaram o histórico da homeopatia e os seus princípios básicos. Em seguida, com a ajuda do agricultor dessa propriedade, coletaram-se carrapatos e bernes dos bovinos. Os ectoparasitas foram adicionados em um frasco na proporção de $40 \%$ do parasita para $60 \%$ de álcool a $70 \%$, produzindo a tintura, que ficou durante 14 dias nessa solução.

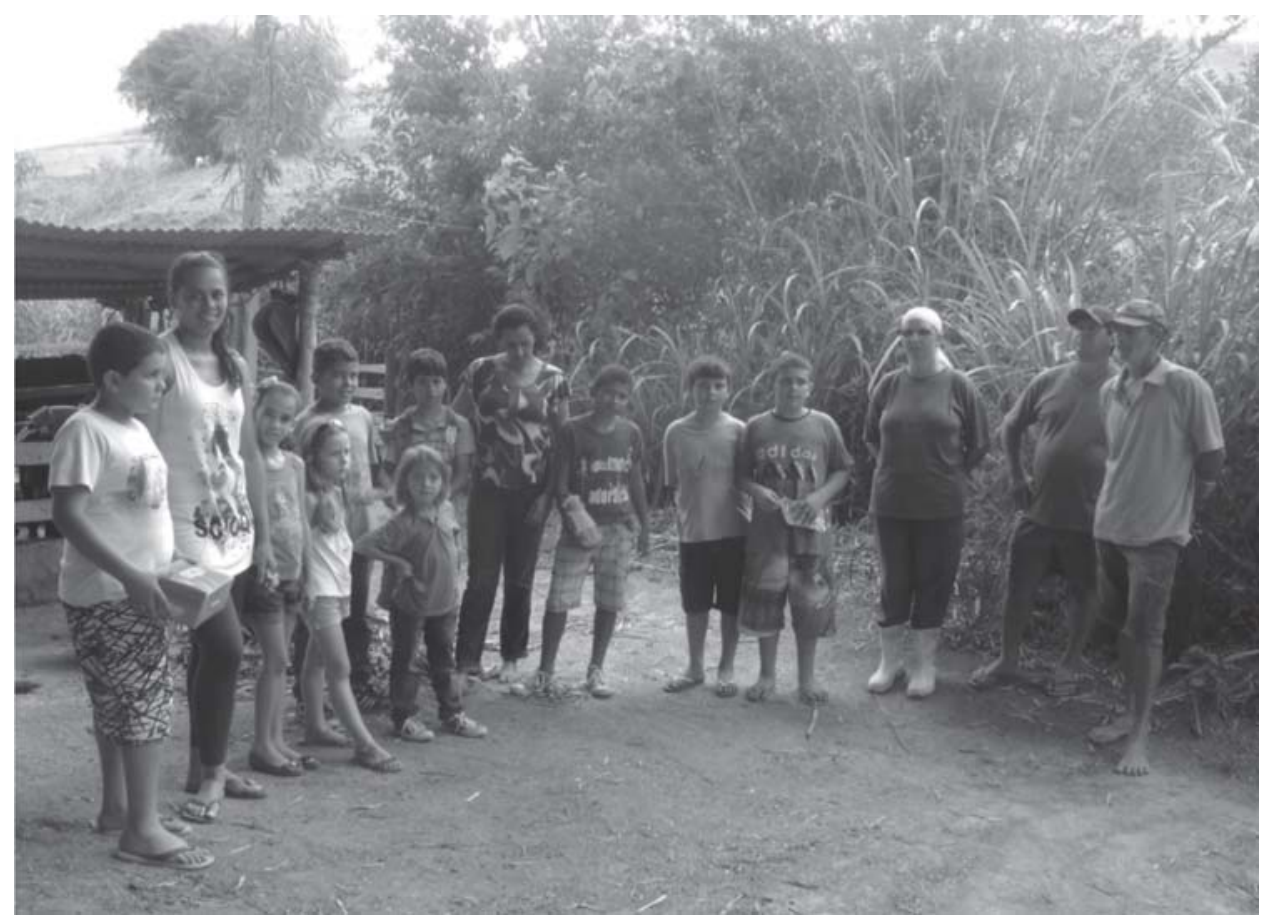

Figura 1 - Visita às famílias do campo

Fonte: Acervo Pessoal

Na visita à segunda propriedade, uma rodada de conversa também foi realizada com participação dos produtores. Os alunos falaram sobre os parasitas estudados em sala de aula e apresentaram a homeopatia com alternativa. Em seguida, foi realizada a coleta dos parasitas dessa propriedade e confecção da tintura (Figura 2). 


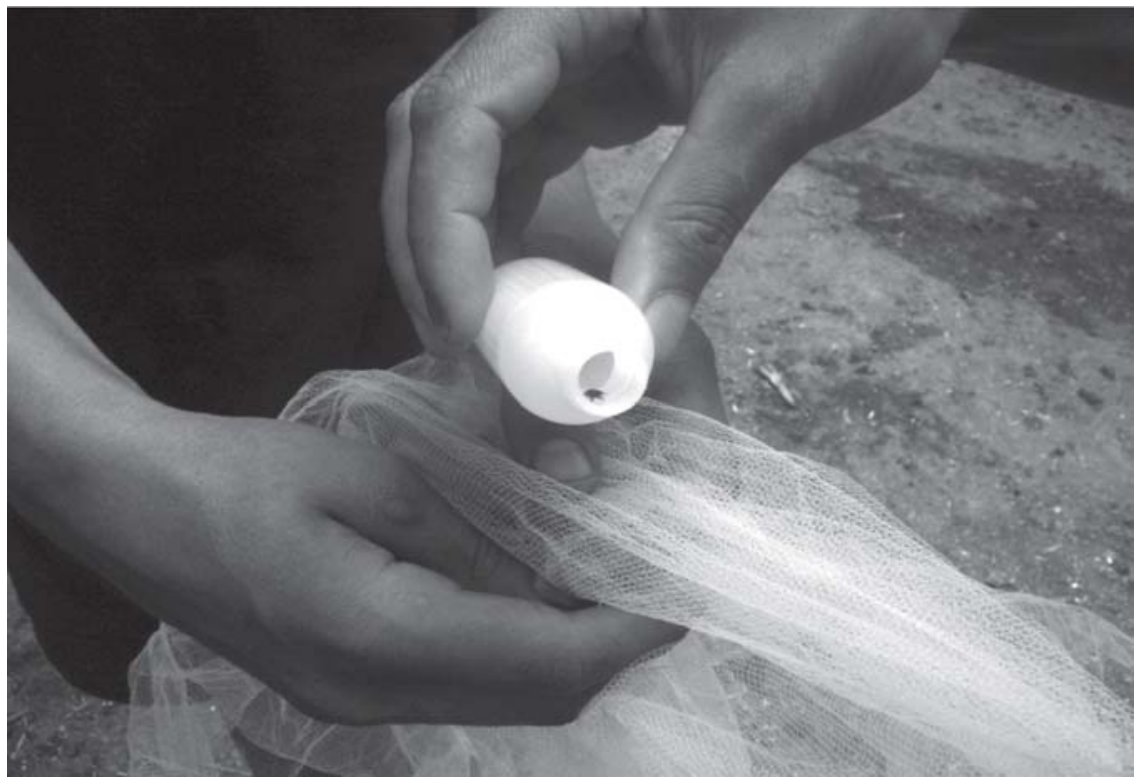

Figura 2 - Coleta dos parasitas nas propriedades para confecção da homeopatia Fonte: Acervo Pessoal

Na segunda etapa do projeto, os alunos retornaram a propriedade do primeiro agricultor visitado para a confecção da homeopatia. Para isso, foi realizado o processo de produção homeopática descrito acima, se utilizando das mesmas proporções (5 gotas da tintura do parasita para $20 \mathrm{~mL}$ de álcool (70\%) submetido a agitação), que contou com a participação dos agricultores. Foram confeccionadas homeopatias para todos os ectoparasitas (berne, mosca e carrapato). Em seguida, para a preparação do sal homeopatizado, pegou-se 50 gotas de cada homeopatia confeccionada e a misturou em $30 \mathrm{~kg}$ de sal mineral (Figura 3). Os produtores ajudaram a preparar a mistura a ser oferecida aos bovinos diariamente e ao longo de todo o ano. As atividades descritas anteriormente também foram realizadas na outra propriedade participante do projeto.

A partir das aulas de campo, os alunos do $1^{\circ}$ ao $5^{\circ}$ ano elaboraram relatórios e o aluno da educação infantil registrou as visitas com desenhos.

Na finalização do projeto houve um momento de confraternização envolvendo toda comunidade escolar, com apresentações dos alunos sobre as descobertas feitas ao longo de todo o projeto, visualização de fotos em data show e degustação de alimentos derivados do leite, fornecido pelos pais dos alunos, e sendo esse leite saudável, já homeopatizado.

\section{Resultados e discussão}

Os agricultores participantes do projeto tornaram a homeopatía uma alternativa diária e eficaz no controle de parasitas dos bovinos em suas propriedades. Como os agricultores aprenderam, na prática, a produzir a homeopatia, eles continuaram utilizando-a mesmo com o término do projeto.

O prazer das crianças no desenvolver do projeto foi evidente, a facilidade com que a maioria dos alunos do $5^{\circ}$ ano compreendeu a porcentagem foi surpreendente, bem como o interesse dos pais por meio da participação e da troca de experiências. As crianças produziram fichas técnicas corretamente e escreveram relatórios coerentes. Os conhecimentos matemáticos foram construídos na prática da homeopatia, (numerais, porcentagem e medidas) e comprovados através de resolução de problemas.

Uma das maiores contribuições deste projeto foi no sentido de mobilizar as famílias dos agricultores, por intermédio da escola, capacitando-os a produzir, a partir do uso da homeopatia, um leite saudável e livre de substâncias tóxicas. Isso foi possível na medida em que os alunos da escola incorporaram os conceitos propostos no projeto e repassaram seu conhecimento à comunidade na qual estão inseridos. 


\section{Conclusões}

Conhecer a comunidade e estreitar as relações entre ela e a escola contribui para que a educação se torne responsabilidade de todos. Este projeto possibilitou que os agricultores (pais dos alunos) tomassem conhecimento de práticas sustentáveis, acessíveis e que respeitam o meio ambiente e todos os seres que fazem parte dele. Conclui-se que com o gado homeopatizado, o leite será melhorado e, com esses conhecimentos conquistados, todos serão beneficiados.

\section{Fontes de financiamento}

A pesquisa não recebeu financiamento para a sua realização.

\section{Agradecimentos}

Aos agricultores familiares que apoiaram e participaram do trabalho.

\section{Referências}

ARENALES, M.C.; MORAES, A.; MORAES, F. Evaluation of the use of homeopathic products for the control of parasites and weight in Indian cattle (nelore), in Brazil. In: WORLD BUIATRICS CONGRESS, 24. Nice, 2006. Anais Nice: European College of Bovine Health Management Science; 2006.

BRASIL. Ministério da Agricultura, Pecuária e Abastecimento/MAPA. Instrução Normativa MAPA $n^{\circ}$ 007, de maio 1999, dispõe sobre normas para a produção de produtos orgânicos vegetais e animais.

FRANÇA, C.G.; DEL GROSSI, M.E.; MARQUES, V.P.M.A. O censo agropecuário 2006 e a agricultura familiar no Brasil. Brasília, MDA, 2009. 95 p.

PINTO, L.F.; ALMEIDA, B. M. O Contexto da Homeopatia na Pecuária Orgânica no Brasil. Homeopatia Brasileira, v. 8, p. 23-28, 2002.

TIBA, I. Disciplina, limites na medida certa: novos paradigmas. São Paulo, Integrare Editora, 2006.

UNIVERSIDADE FEDERAL DE VIÇOSA/UFV. Caderno de Homeopatia. Viçosa, 2014.

Recebido para publicação em 18/2/2018 e aprovado em 23/7/2018. 